\title{
CARACTERIZAÇÃO DE CEPAS DO TRYPANOSOMA CRUZI ISOLADAS DE DOENTES NOS QUAIS FOI REALIZADO TRANSPLANTE DE CORAÇÃO
}

\author{
Perla Natalia Bustos Lanura, Luis Matsubara, Vicente Amato Neto, \\ Masayuki Okumura e Edimar Alcides Bocchi
}

\begin{abstract}
Três cepas do Trypanosoma cruzi foram isoladas de pacientes com doença de Chagas crônica, receptores de coração por meio de transplante. Houve caracterização delas através de modelo experimental baseado no emprego de camundongos, com avaliação de parasitismo, mortalidade e intensidade da inflamaçâa no coração, além de análise do grau de parasitismo nesse órgão. Como controle, teve lugar comparação com o comportamento da jâ bem conbecida cepa Y. Ficaram caracterizadas atuaçōes diferentes das cepas, ao serem valorizados os parâmetros citados, sem correlação rigorosa com as evoluçōes pós-transplantes, que sofrem a influência de värios fatores, entre os quais podem estar particularidades vinculadas ao parasitismo.
\end{abstract}

Palauras-chaves: Doença de Chagas crônica. Transplante de coração. Cepas do Trypanosoma cruzi. Caracterizaçâo.

Presentemente, está em vigor nova modalidade de tratamento da cardiopatia que faz parte da doença de Chagas crônica. Tratase do transplante de coração, indicado quando o paciente não se beneficia mais da adoção das medidas convencionais ${ }^{4}$.

Em São Paulo, no Instituto do Coração do Hospital das Clínicas, da Faculdade de Medicina da Universidade de São Paulo, encontra-se em desenvolvimento programa para realização desse tipo de transplante e, no decurso dele, várias questões vêm sucedendo, de molde a suscitar esclarecimentos ${ }^{1013}$. Entre tais assuntos, por exemplo, lembramos a reativação parasitária, o quadro clínico modificado, a terapêutica específica e a ocorrência complicadora de doenças oportunísticas. Desse contexto, portanto, participam múltiplas circunstâncias, merecedoras de investigações e, a propósito, consideramos conveniente abordar aspecto eventualmente interessante, representado por diferentes cepas do Trypanosoma cruzi envolvidas.

Laboratório de Investigacão Médica - Parasitologia do Hospital das Clínicas da Faculdade de Medicina da Universidade de São Paulo, São Paulo, SP

Endereço para correspondência: Prof. Vicente Amato Neto. Divisão de Clínica de Moléstias Infecciosas e Parasitárias/IC/IIC - $4^{\circ}$ andar, s/4028. Av. Dr. Arnaldo 455 , 01246-000 São Paulo, SP, Brasil.

Recebido para publicação em 03/11/94.
Estudos experimentais em animais e relatos de fatos sucedidos com enfermos, quando presente imunodepressão, revelaram diversas particularidades, sendo uma delas o comportamento desigual de cepas ${ }^{23568}$. Assim, parece sensato analisar essa faceta no âmbito do transplante de coração, pois evolução, configuração clínica e prognóstico quiçá tenham relação com o referido detalhe.

Até o momento, pudemos analisar, em modelo experimental, baseado no emprego de camundongos, as infecções causadas por três cepas que isolamos e, agora, comunicamos as verificações pertinentes.

\section{MATERIAL E MÉTODOS}

As cepas provieram de três pacientes do sexo masculino (CCC, JVR, JRAC) Com 13, $16 \mathrm{e}$ 34 anos de idade, respectivamente. Obtivemos o parasita através de xenodiagnóstico in vitro, efetuado no segundo ou terceiro mês póstransplante. Suspendemos as fezes dos insetos em solução fisiológica e injetamos em camundongos, aleatoriamente, sem contar as formas parasitárias, uma vez que é problemática a determinação de epimastigotas e tripomastigotas nessa condição.

A partir desses animais, constituímos quatro grupos: CCC, JRV, JRAC e o correspondente à cepa $\mathrm{Y}$, de há muito mantida no Laboratório e utilizada como controle. Para analisar parasitemia e mortalidade empregamos lotes 
Lanura PNB, Matsubara L, Amato Neto V, Okumura M, Bocchi EA. Caracterização de cepas do Trypanosoma cruzi isoladas de doentes nos quais foi realizado transplante de coração. Revista da Sociedade Brasileira de Medicina Tropical 28:351-356, out-dez, 1995.

de camundongos Balb/C, fêmeas, pesando de 18 a $20 \mathrm{~g}$ e, a fim de apreciar histologicamente o coração, com o intuito de procurar as formas teciduais do $T$. cruzi e o componente inflamatório, além de prever a execução de provas sorológicas, compusemos conjuntos de 12 ou de 14 quanto à JVR.

Os inóculos provieram dos animais infectados e anestesiados por meio do éter sulfúrico, mediante punção cardíaca e uso de seringa heparinizada; cada um contou com $10^{4}$ formas tripomastigotas e as inoculações foram sempre intraperitoneais. Praticamos as contagens com câmara de Neubauer, expressando-as em tripomastigotas $/ \mathrm{ml}$.

A propósito da parasitemia e da mortalidade, a partir do terceiro dia, efetuamos contagens diárias no sangue retirado da cauda, até as mortes ou negatividades às pesquisas do parasita; referimos os números encontrados em 5ul, calculando-os pelas médias geométricas.

Coramos as preparações histológicas com $5 \mu$ de espessura, pela hematoxilina-eosina, tendo a fixação sido feita com formol a 10\%. Para obtê-las sacrificamos dois camundongos de cada grupo, em diferentes fases da infecção, ou seja, início, época da maior parasitemia e final da experiência. Determinamos os graus de parasitismo, em cada órgão, examinando cortes obtidos pela secção perpendicular ao septo, de molde a ficar viável contar nas quatro câmaras, estabelecendo médias geométricas das quantidades de "ninhos" de amastigotas. No que diz respeito às intensidades inflamatórias, catalogamo-as como leves, moderadas ou intensas.

Nas ocasiōes dos sacrificios coletamos sangue para a execução de provas com soros primeiro conservados a $-20^{\circ} \mathrm{C}$. Esses testes foram: imunofluorescência indireta, com título de $1 / 90$ do conjugado antigamaglobulina total de camundongo; hemaglutinação indireta, com utilização de placas de microtitulacão e hemácias de ganso sensibilizadas por antígeno protéico de formas amastigotas do $T$. cruzi.

\section{RESULTADOS}

Qualificamos a parasitemia como baixa, média ou alta, computando o momento do nível máximo em dias, o número de tripomastigotas em $5 \mu l$ e a época do desaparecimento ou morte. Dessa forma, enquadramos assim as cepas: baixa-JRAC; média-CCC e JVR; alta-Y. A Figura 1 mostra globalmente o verificado sob esse aspecto.

A cepa $Y$ desencadeou elevada parasitemia e mortalidade de $100 \%, 14$ ou 15 dias após a

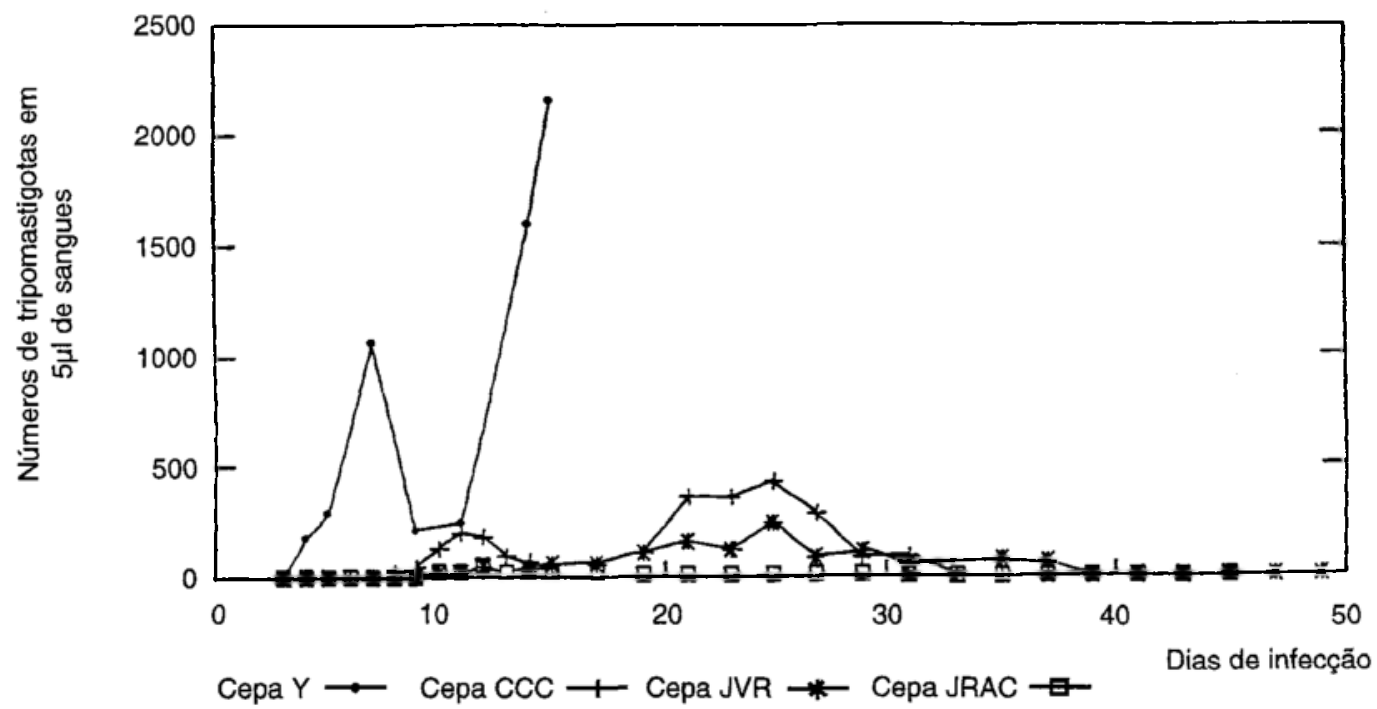

Figura 1 - Niveis máximos e evoluçôes das parasitemias, nos dias em que foram determinados, conforme as cepas. 
Lanura PNB, Matsubara L, Amato Neto V, Okumura M, Bocchi EA. Caracterização de cepas do Trypanosoma cruzi isoladas de doentes nos quais foi realizado transplante de coração. Revista da Sociedade Brasileira de Medicina Tropical 28:351-356, out-dez, 1995.

infecção. A CCC originou parasitemia de grau mediano e $40 \%$ de mortalidade, entre os dias 27 e 37 posteriores à inoculação do parasita. As JVR e JRAC, por sua vez, condicionaram escassa parasitemia, sem mortalidade.

Histologicamente, variaram as intensidades dos infiltrados inflamatórios linfoplasmocitários com edema intersticial e as quantidades de "ninhos". As cepas Y e CCC causaram inflamação indo de grau moderado a intenso, com expressivo parasitismo no coração; a JVR coadunou-se com discreta inflamação e leve parasitismo, enquanto que a propósito da JRAC esses parâmetros apresentaram-se como discreto e situado de leve a moderado, respectivamente (Figuras $2 \mathrm{e}$ 3).

À prova de imunofluorescência indireta vimos elevações graduais dos teores de anticorpos, permanecendo isso até o final quando eram Y e a CCC as cepas e decaindo ao término da infecção nos casos das outras duas (Figura 4). A hemaglutinação nunca revelou positividades.

\section{DISCUSSÃO}

Fundamentalmente, foi-nos possível constatar diferentes virulências $e$, agindo semelhantemente à caracterização proposta por Schlemper e cols ${ }^{9}$, deduzimos que a cepa Y situou-se no tipo III, por ser alta, a CCC no II, tida como média e as JVR e JRAC no I, por terem-se portado como baixas. Parasitemia, mortalidade, intensidade da inflamação e grau de parasitismo no coração, em conjunto, constituíram os marcadores que justificam essa gradação.

Houve produção de anticorpos, com decurso desigual, conforme ficou exposto. Vale comentar que as diminuições sucederam justamente nos infectados pelas cepas catalogadas como menos virulentas.

Não pesquisamos os anticorpos da classe IgM, antitripanossoma, desde que recorremos a conjugado antigamaglobulina total de camundongo. Por isso, ficamos sem melhor informação sorológica acerca do começo da infecção.

As constantes negatividades apuradas quando empregada a hemaglutinação ficam anotadas, sem boa explicação de nossa parte. $O$ antígeno protéico tem nexo com a revelação de anticorpos da categoria IgG e, então, pelo menos eles poderiam ficar revelados.

É justo frisar que, sem dúvida, não se comportaram identicamente as cepas, tendo

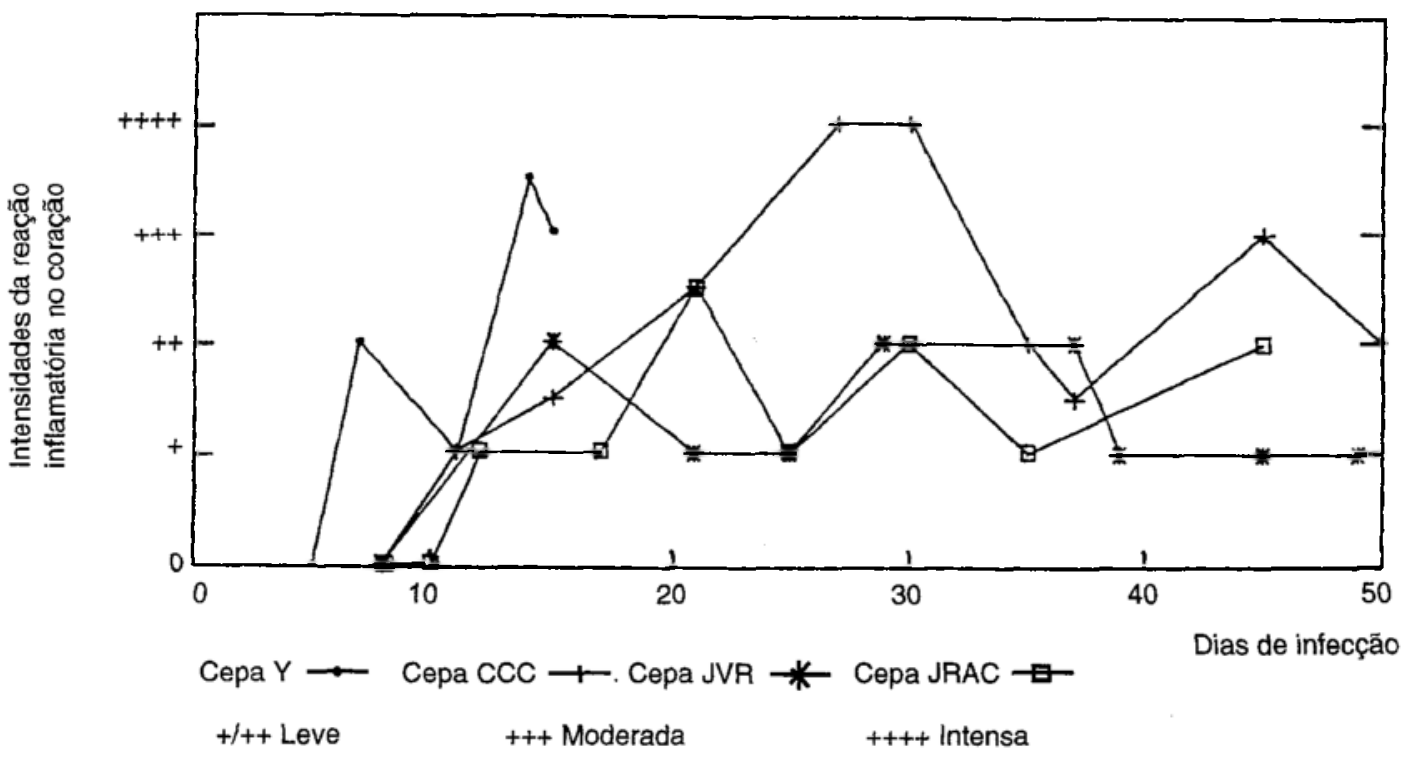

Figura 2 - Intensidades das reaçöes inflamatórias nos corações, nos dias em que foram avaliadas, conforme as cepas. 
Lanura PNB, Matsubara L, Amato Neto V, Okumura M, Boccbi EA. Caracterização de cepas do Trypanosoma cruzi isoladas de doentes nos quais foi realizado transplante de coração. Revista da Sociedade Brasileira de Medicina Tropical 28:351-356, out-dez, 1995.

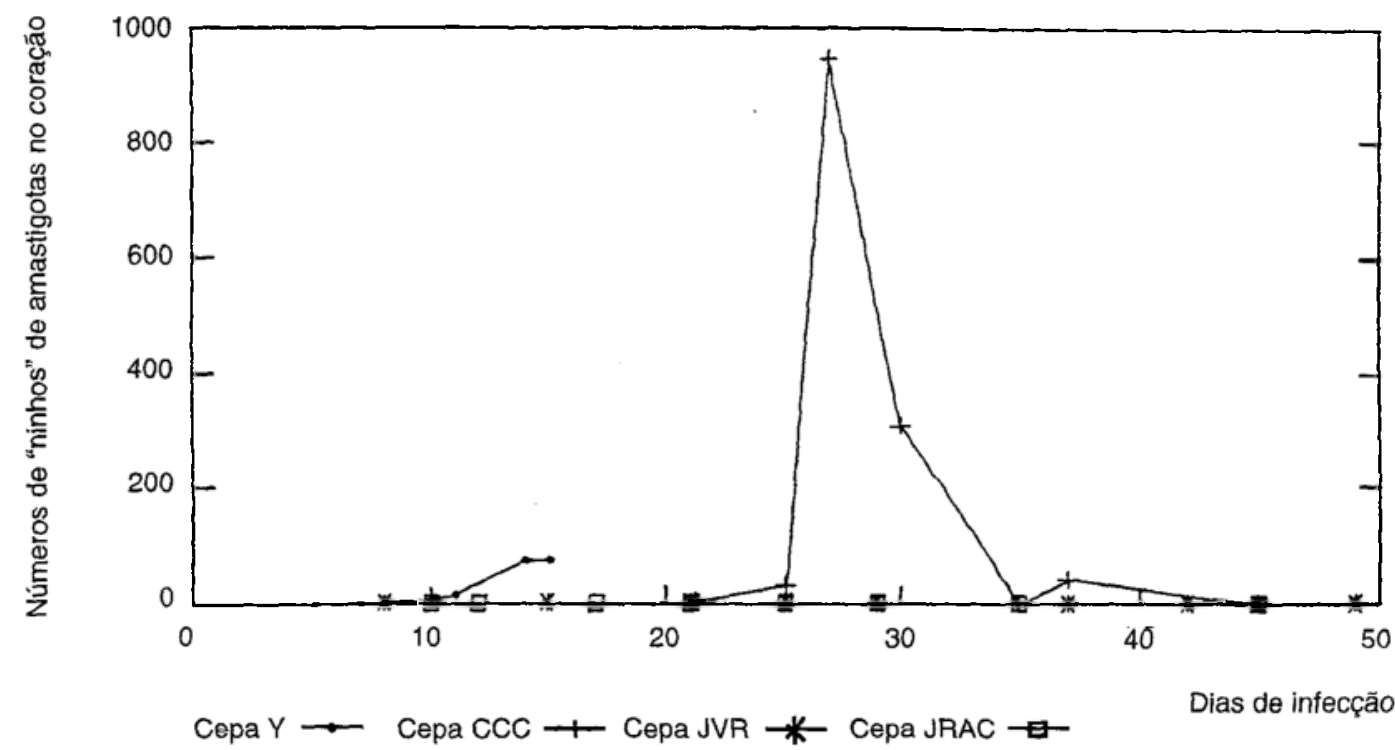

Figura 3 - Nümeros de "ninhos" de amastigotas nos coraçōes, nos dias em que foram contados, conforme as cepas.

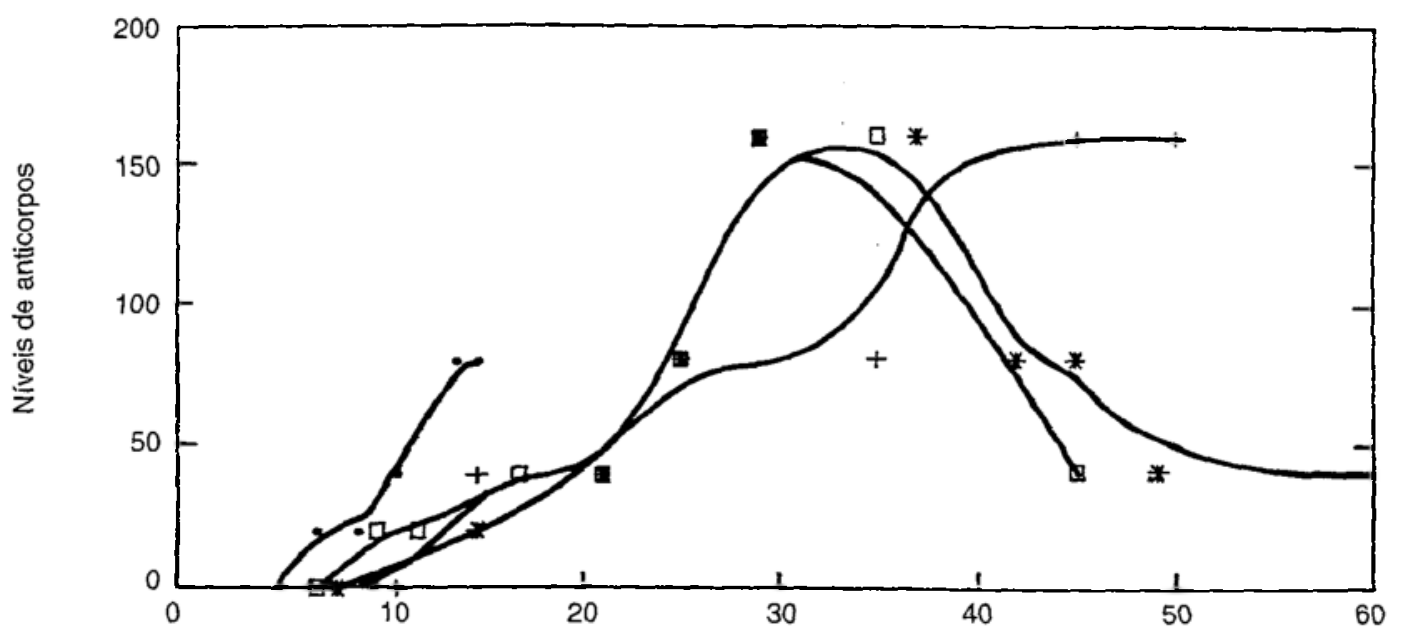

CepaY $\rightarrow$ Cepa CCC $\longrightarrow$ Cepa JVR $\rightarrow$ CepaJRAC $\square-$

Dias de infecção

Figura 4 - Niveis de anticorpos IgG antitripanossomo, nos dias em que foram determinados, pela reação de imunofluorescência indireta e expressos em diluiçoes dos soros, conforme as cepas. 
Lanura PNB, Matsubara L, Amato Neto V, Okumura M, Bocchi EA. Caracterização de cepas do Trypanosoma cruzi isoladas de doentes nos quais foi realizado transplante de coraçấo. Revista da Sociedade Brasileira de Medicina Tropical 28:351-356, out-dez, 1995.

isso eventuais conotações com a evolução pós-transplante. Especulativamente, essa contigência pode ser levada em conta e suscitar avaliações mais profundas. Quanto ao que fizemos, procuramos comparar as três modalidades analisadas com o que ocorreu com os pacientes correspondentes, valorizando principalmente os acontecimentos depois dos transplantes, números de rejeiçôes, reativaçôes clínico-parasitológicas e agressões inflamatórias aos corações, com ou sem presença do $T$. cruzi. Lembramos que fazem parte dos acompanhamentos as cintilografias miocárdicas com um gálio e as biópsias endomiocárdicas. Apuramos, então, que percalços maiores sucederam no doente JVR, sendo intermediárias as intercorrências em CCC e de menor porte no JRAC. Assim, não vimos rigorosas correlações. Não obstante, as discrepâncias não foram marcantes, estando os enfermos vivos por ocasião do preparo deste texto. As diversidades evolutivas, antes citadas, configuram detalhes valorizados para consubstanciar a investigação realizada.

Para o sucesso do transplante intervêm diversos fatores influentes, numa conjuntura que envolve o parasita, a imunodepressão, a atuação medicamentosa frente à eventual reativação e os números de rejeições ou pulsoterapias, ao lado de outros. Aqui focalizamos um deles, estimulando maiores e mais profundos estudos sobre o item referente à virulência da cepa envolvida.

\section{SUMMARY}

Three strains of Trypanosoma cruzi were isolated from Chagas' disease patients transplanted for beart failure, after cardiac transplantation, and were studied in an experimental model of Chagas' disease, in mice, with evaluation of parasitic load, mortality and extension of inflammatory infiltrates in the beart. These parameters were compared with the standard strain $Y$. The strains bad differences in the studied parameters, but there was no clear relationship between those and post-transplant evolution of the patients. Probably the clinical response is multifactorial and derives only in part from biological characteristics of the infecting $\mathrm{T}$. cruzi strain, as measured in our model.

Key-words: Cbronic Chagas' disease. Heart transplantation. Strain characteristics of Trypanosoma cruzi.

\section{REFERÊNCIAS BIBLIOGRÁFICAS}

1. Amato Neto V, Matsubara L, Uip DE, Strabelli TMV, Bocchi EA, Stolf NAG, Jatene AD. Transplante de coração: doador com doença de Chagas e evolução do receptor. Revista do Hospital das Clínicas da Faculdade de Medicina de São Paulo 47:92-93, 1992.

2. Andrade SG. Caracterização de cepas do Trypanosoma cruzi isoladas no Recôncavo Baiano (Contribuição ao estudo da patologia geral da doença de Chagas em nosso meio). Revista de Patologia Tropical 1:65-121, 1974.

3. Andrade $S G$, Carvalho ML, Figueira RM. Caracterização morfobiológica e histopatológica de diferentes cepas do Trypanosoma cruzi. Gazeta Médica da Bahia 70:32-42, 1970.

4. Bocchi EA. Imunossupressão na doença de Chagas. Aspectos clínicos-cardiológicos na imunossupressão. Revista da Sociedade Brasileira de Medicina Tropical 20(supl II ):M39-M41, 1987.

5. Brener Z, Chiari E. Variações morfológicas observadas em diferentes amostras de Trypanosoma cruzi. Revista do Instituto de Medicina Tropical de São Paulo 5:220-224, 1963.

6. Chocair PR, Amato Neto V, Sabbaga E, Torrecillas $\mathrm{PH}$.Aspectos clínico-diagnósticos relativos à fase aguda da doença de Chagas, em pacientes submetidos a transplante de rim e imunodeprimidos. Revista da Sociedade Brasileira de Medicina Tropical 18:43-45, 1985.

7. Dias JCP, Jatene AD. Doença de Chagas no Brasil. Situação atual e perspectivas. Revista da Sociedade Brasileira de Medicina Tropical 25(supl III):6-8, 1992.

8. Okumura M, Amato Neto V, Campos R, Silva AF, Moreira AAB, Souza HBWT, Pinto PLS, Matsubara L. Influência da ciclosporina e da prednisona na fase aguda da infecção experimental de camundongos pelo Trypanosoma cruzi. Revista do Hospital das Clínicas da Faculdade de Medicina de São Paulo 45:53-56, 1990

9. Schlemper Jr BR, Ávila CM, Coura JR, Brener Z. Course of infection and histopathological lesions in mice infected with seventeen Tyrpanosoma cruzi strains isolated from chronic patients. Revista da Sociedade Brasileira de Medicina Tropical 16:23-30, 1983.

10. Stolf NAG, Higushi L, Bocchi E, Bellotti G, Auler JOC, Uip D, Amato Neto V, Pileggi F, Jatene AD. Heart transplantation in patients with Chagas' 
Lanura PNB, Matsubara L, Amato Neto V, Okumura M, Boccbi EA. Caracterização de cepas do Trypanosoma cruzi isoladas de doentes nos quais foi realizado transplante de coração. Revista da Sociedade Brasileira de Medicina Tropical 28:351-356, out-dez, 1995.

disease cardiomyopathy. The Journal of Heart Transplantation 6:307-312, 1987.

11. Uip DE, Strabelli TMV, Bellotti G, Bocchi EA, Stolf N, Pileggi F, Jatene AD, Amato Neto V. Evolucão clínica de pacientes com doença de Chagas submetidos a transplante cardíaco. Revista da Sociedade Brasileira de Medicina Tropical 20(supl ID: $24,1987$. 